\title{
perifèria
}

Número 9, diciembre 2008

$\underline{\text { www.periferia.name }}$

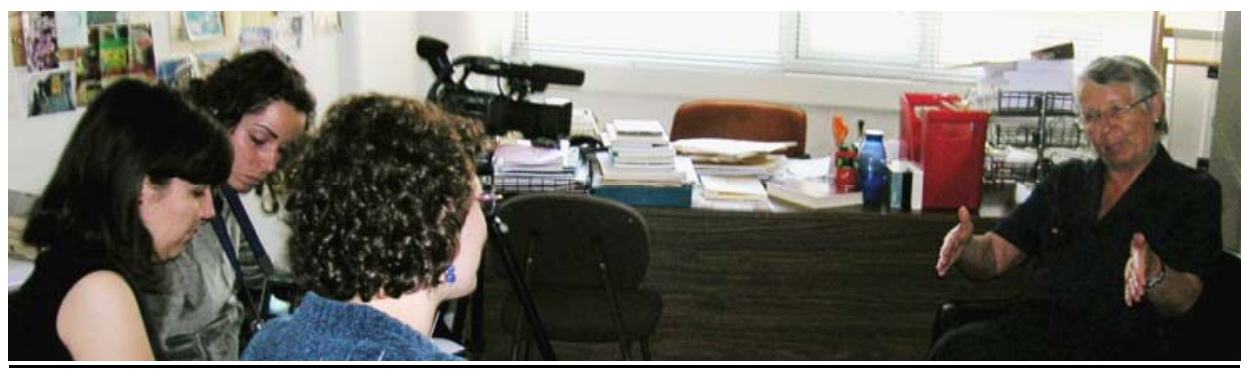

\section{"En toda teoría hay algo de biografía" Entrevista a Verena Stolcke}

\author{
Autor/a: ${ }^{1}$ Clua, Montserrat; Tamarit, Laura; Ribas, Fina; Blasco, Roser \\ Universidad: Universitat Autònoma de Barcelona
}

\section{Resum:}

En aquesta ocasió el Projecte Entrevistes ${ }^{2}$ entrevista a la catedràtica Verena Stolcke, sumant-se així als actes d'homenatge que se li van fer el maig de 2008, arran de la seva jubilació del Departament d'Antropologia Social i Cultural de la Universitat Autònoma de Barcelona, després de més de trenta anys exercint-hi la docència. A través de l'entrevista es pot conèixer part de la trajectòria personal i intel-lectual de la professora Stolcke, una biografia estretament vinculada als temes que l'han interessat i que ha desenvolupat al llarg de la seva obra. Paral-lelament a

\footnotetext{
${ }^{1}$ Enviar correspondencia a: Montserrat.clua@uab.cat

2 El Projecte Entrevistes està vinculat a l'assignatura "Etnologia Regional" que Montserrat Clua imparteix a la Llicenciatura d'Antropologia Social de la UAB. A curt termini el projecte pretén que els/les alumnes posin en pràctica continguts i capacitats de la seva formació com a antropòlegs a través de la realització d'una entrevista personal. A mitjà i llarg termini el projecte pretén crear un fons documental sobre la trajectòria vital i intel-lectual de destacats antropòlegs espanyols per millorar l'escàs fons disponible sobre la història de la disciplina a Espanya i que sigui consultable per a les següents promocions.
} 


\section{perifèria}

Número 9, diciembre 2008

www.periferia. name

aquest recorregut vital la Dra. Stolcke ens ofereix la seva visió de la situació en què es trobava l'antropologia catalana i espanyola quan va arribar a casa nostra, així com un diagnòstic de la situació actual de la disciplina, que afronta un dels seus reptes més importants amb el procés d'adaptació a l'Espai Europeu d'Educació Superior (conegut com a Procés Bolonya).

\section{Resumen:}

En esta ocasión, el Proyecto Entrevistas ${ }^{3}$ entrevista a la catedrática Verena Stolcke. De esta forma se suma a los actos de homenaje que se le rindieron en mayo de 2008, en ocasión de su jubilación del Departamento de Antropología Social y Cultural de la Universidad Autónoma de Barcelona, después de más de treinta años de docencia. A través de la entrevista se puede conocer parte de la trayectoria personal e intelectual de la profesora Stolcke, una biografía estrechamente relacionada con los temas que más le han interesado y que ha desarrollado a lo largo de su obra. Simultáneamente a este recorrido vital, la Dra. Stolcke nos ofrece su visión de la situación en que se hallaba la antropología catalana y española cuando llegó a nuestro país, así como un diagnóstico de la situación actual de la disciplina, que se enfrenta a uno de sus retos más importantes con el proceso de adaptación al Espacio Europeo de Educación Superior (o también llamado Proceso Bolonia).

Fina Ribas: Hace poco te hicieron el homenaje por toda tu trayectoria en la Universidad Autónoma de Barcelona y pronto empezarás como profesora emérita en el departamento de Antropología Social y Cultural. ¿Cómo te sientes?

\footnotetext{
${ }^{3}$ El Proyeco Entrevistas está vinculado a la asignatura "Etnología Regional" que Montserrat Clua imparte en la Licenciatura de Antropología Social de la UAB. A corto plazo el proyecto pretende que los/las alumnos/as pongan en práctica contenidos y capacidades de su formación como antropólogos a través de la realización de una entrevista personal. A medio y largo plazo el proyecto pretende crear un fondo documental sobre la trayectoria vital e intelectual de destacados antropólogos/as españoles para mejorar el escaso fondo disponible sobre la historia de la disciplina en España y que sea consultable por las siguientes promociones.
} 


\section{perifèria}

Número 9, diciembre 2008

www.periferia.name

Verena Stolcke: Yo me siento muy, muy bien. A ver, es un proceso un poco lento... El homenaje fue absolutamente memorable; para mi fue una experiencia única. Durante el homenaje ni me di cuenta de todo lo que estaba pasando: que hubierais llamado a mis amigos, colegas de Brasil, Peter Fry, con los que empecé a dar clases de antropología... Eso fue muy bonito. Pero ayer estuve ordenando los papeles de las asignaturas...Me siento tan aliviada! Conseguí meterlos todos en el ordenador, en archivadores y... y ya está. Ahí están, es lo que hay; en cuando quiera puedo rescatar alguna cosa. Le recomiendo a todo el mundo que se jubile cuanto antes [nos reímos].

F: Y ahora, con la jubilación, tendrás mucho más tiempo que no tenías porque te descargaste de las clases. ¿En qué proyectos estás trabajando o estas pensando?

VS: Tendré relativamente más tiempo, porque daré una asignatura de "Antropología de género", en el Master Oficial. ${ }^{4}$ Después participo en otra asignatura del Master, que es la de "Identidades ambivalentes" que hacemos desde AHCISP. ${ }^{5} \mathrm{Y}$ además doy una asignatura en un master, que también es oficial, del Institut Interuniversitari d'Estudis de Gènere i Dona, de Cataluña. Así que no es tan poco, pero sobretodo es una forma de mantener el contacto, que es muy bonito.

\section{F: Y como presidenta del ICA (Institut Català d'Antropologia), que eres desde ya hace unos cuantos años...}

VS: Me sorprendió el otro día, durante el acto de homenaje, cuando lo decía Manuel Delgado. Además es muy divertido porque, claro, en principio tendría que constar

\footnotetext{
4 Se refiere al Master Oficial en Investigación Etnográfica, Teoría Antropológica y Relaciones Interculturales que se imparte en la Universidad Autónoma de Barcelona.

${ }^{5}$ Se refiere a "Mestizajes: a propósito de identidades ambivalentes", una asignatura del Master Oficial del departamento y que imparten de forma colectiva los investigadores del grupo de investigación AHCISP (Antropología e Historia de la Construcción de Identidades Sociales y Políticas) dirigido por las doctoras Verena Stolcke y Montserrat Ventura.
} 


\section{perifèria}

Número 9, diciembre 2008

www. periferia. name

en los estatutos que el mandato tiene un término, un tiempo limitado. Pero yo creo que no lo pusieron porque es bastante difícil encontrar personas que quieran meterse en este tipo de follón. Yo lo paso muy bien como presidenta. Entonces ahora, como tendré más tiempo...

\section{F: ¿Cómo ves, desde la presidencia del ICA y desde tu posición de profesora emérita, la situación de la antropología catalana y española?}

VS: Yo creo que ha habido dos, tres procesos en los últimos años que están contribuyendo a la mayor disciplinariedad de la antropología. Por una parte, toda la preparación del grado y la movilización por el grado. Es bastante notable que una parte de las antropólogas y los antropólogos se manifestaran delante del ministerio en Madrid. Y yo creo que esto ha surtido algún efecto. Pero claro, es un efecto que no va solo, sino que el Institut Català d'Antropologia, de hecho en los últimos años (yo diría cinco o seis), hemos conseguido hacer bastantes más actividades, y es bastante más conocido y reconocido. Tenemos una vinculación con el Institut d'Estudis Catalans (IEC), que es la academia catalana, y esto es fantástico, porque finalmente quiere decir también más reconocimiento. Tenemos un convenio con el $\underline{I P E C}$, que es el Inventari del Patrimoni Etnològic Català. $Y$ además estamos en el proceso de creación de un colegio profesional de antropología. Hay un problema con el nombre, porqué no queremos que sea un colegio de antropólogos y de antropólogas, sino de antropología. Pero claro, una profesión son personas. Entonces esto es un debate. Pero el colegio está en camino. Tenemos a Nani Ibáñez, que es antropóloga y jurista, que está llevando este tema yo creo que con mucho éxito y con mucha empenta ${ }^{6}$.

\footnotetext{
${ }^{6}$ Empenta significa “empuje, energía, fuerza” en catalán.
} 


\section{perifèria}

Número 9, diciembre 2008

www.periferia.name

F: Y más concretamente, a nivel académico, ya que has comentado el proceso de construcción del Grado en Antropología para la adaptación al Espacio Europeo de Educación Superior lo también llamado Proceso Bolonia), ¿cómo ves estos cambios que se llevaran a cabo en la carrera o en el grado de antropología?

VS: Mira, os lo diré pero muy brevemente: yo tuve la suerte de estudiar en Inglaterra, en Oxford. Oxford y Cambridge son sistemas muy específicos, donde tú estudias en un sistema de tutoría, individual o un tutor tiene dos o tres alumnos. Yo tenía uno, es decir, era una relación de uno a uno, con tutorías semanales. Y tenía que escribir un ensayo con la bibliografía indicada (este tipo de ensayos que os hago hacer) semanal. Esto debería ser (tal vez con una relación o una proporción un poco menos benevolente, es decir, un profesor con cinco estudiantes), el formato de Bolonia. Pero no hay recursos. O no hacen disponibles los recursos para que efectivamente el paso al sistema Bolonia de trabajo, de investigación, de estudios más personales, en vez de aulas magistrales como dicen, pueda funcionar. Porque, ¿qué haces con un grupo de cincuenta estudiantes? Es imposible con el profesorado que tenemos. Somos muy poca gente.

\section{F: O sea, que ¿el problema seria de los recursos?}

VS: ¡Absolutamente! La idea de coste cero es absurda. Y ya lo verán. Lo verán poco con respecto a la antropología, las ciencias sociales y las humanidades... Pero se darán cuenta en las ciencias: química, física, biogenética, etcétera. No se puede. 


\section{perifèria}

Número 9, diciembre 2008

www.periferia. name

"La idea de aplicar el sistema Bolonia a coste cero es absurda."

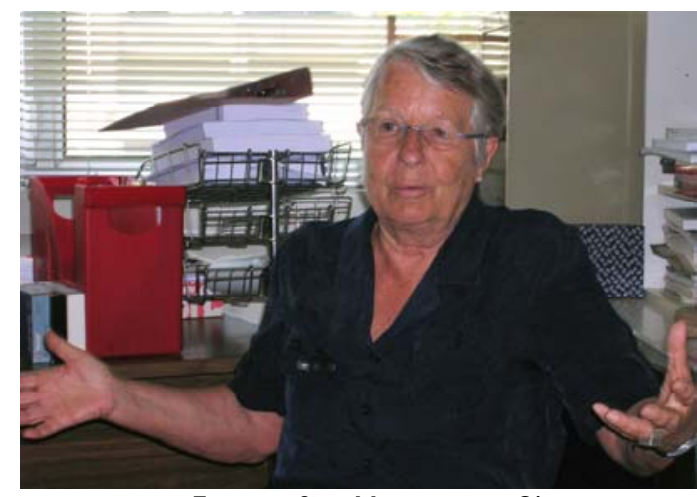

Fotografía: Montserrat Clua

\section{F: Y este cambio que se está llevando a cabo en el Espacio Europeo de Educación Superior, ¿deja mejor situada a la antropología española académica dentro de Europa o dentro del mundo?}

VS: Mira, yo creo que tenemos una larga experiencia detrás, que es el programa Erasmus. ${ }^{7}$ Y por suerte, aquí en el departamento empezamos desde el principio, hace dieciséis o diecisiete años. Y esto hizo que se conociera este departamento específicamente y la antropología de el estado español en Europa. Efectivamente, la gente que ha venido aquí siempre ha traído más demandas tras ella. Esto ha preparado el terreno para una vinculación más fluida con los colegas y las colegas de los países europeos. Yo pienso que nos conocen muy bien. Participamos plenamente en la EASA, la asociación europea de antropología. Creo que los socios y las socias del estado español somos el porcentaje más alto de la EASA, cosa que también es bastante notable. $O$ en algún momento fueron los más numerosos. Yo estoy muy de acuerdo con Bolonia pero a coste cero, no. Esto no tiene sentido.

\footnotetext{
${ }^{7}$ Se refiere al programa de intercambio de estudiantes entre universidades europeas.
} 


\section{perifèria}

Número 9, diciembre 2008

www. periferia. name

\section{Roser Blasco: Estábamos comentando la situación actual. I maginamos que no tiene nada que ver con la situación que te encontraste cuando llegaste aquí.}

VS: No, no tiene nada que ver.

\section{R: Según nuestros datos, tu primera estancia en España fue en Andalucía. ¿Cómo fue que viniste?}

VS: No, no, no es que viniera yo, sino que es una historia.... Bueno, son estas historias de la vida de las personas. Yo conocí a Juan Martínez Alier (que es el padre de mis hijas y que fue mi marido), en la Universidad de Stanford, en California, donde yo era asistente de investigación (un título bastante sofisticado pero en realidad era secretaria). Nos conocimos en el año 62, en la movilización de los estudiantes contra el gobierno Kennedy y su proyecto de intervención en Cuba (y por eso fuimos a Cuba después).Y también en el movimiento estudiantil por la libertad de expresión, el movimiento por los derechos civiles de la población afroamericana. Yo estuve en Palo Alto, que es el pueblo al lado de la Universidad de Stanford. Estuve en el barrio del este, donde vivía la población negra, y registraba electores y electoras, que era una cosa absolutamente ingenua. Era jovencísima, tenía 23 años. Me plantaba delante de puertas, con listas, tratando de persuadir a las personas a inscribirse para votar. En medio de esa agitación conocí a Juan Martínez Alier. Él volvió a España después de un año, estaba haciendo un master, y me escribió desde la campiña de Córdoba, una postal preguntándome si no me quería casar con él. [Nos reímos] 


\section{perifèria}

Número 9, diciembre 2008

www.periferia.name

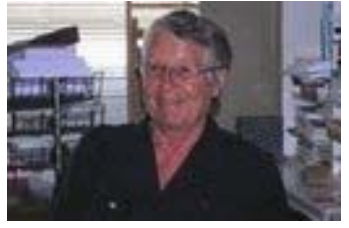

Fotografía: Montserrat Clua

No estaba en absoluto en mis planes casarme. Lo pensé, y de vuelta me quedé un año más [en Stanford]. Cuando regresé a España, Juan ya había vuelto a Oxford, donde estaba haciendo el doctorado, haciendo su tesis sobre el latifundio en la campiña de Córdoba. Fue así como yo llegué en el segundo trabajo de campo de Juan Martínez Alier a la campiña de Córdoba. Vivíamos en la pensión "El arcángel", muy cerca de la mezquita, e íbamos con un Citröen 2CV a visitar los cortijos. Dormíamos en los cortijos y hablábamos con los trabajadores. Era el año 65 y era una situación muy tensa. Sólo después me di cuenta de lo complicada que era políticamente: en el momento en que sacábamos un papel para anotar algo, la gente se cerraba. En Andalucía estaban deteniendo trabajadores y el clima político era tensísimo. Entonces fue ahí donde conocí este país. Fue una instrucción, fue una experiencia ¡extraordinaria! Empezar con la guerra civil y la posguerra civil... Y claro, me veían la cara, los jornaleros y las jornaleras... Estuve con una cuadrilla de mujeres que eran... ¡de un desbocado! Me tomaban el pelo, ¿no? y describían con todo lujo de detalles las noches anteriores con sus maridos, sólo para provocarme... [nos reímos]

Fue una experiencia increíble. Aprendí sobre los hombres de ideas, toda la historia política, el anarquismo en Andalucía, y aprendí también muchísimo sobre la situación del 65. Y me veían a mí, claro, con esa cara de nórdica... y decían que era muy divertido. Juan Martínez Alier es de Barcelona, y es una persona que habla para adentro y además con acento catalán. Entonces le preguntaban: "¿Y usted qué 


\section{perifèria}

Número 9, diciembre 2008

www.periferia.name

es?" Y él decía "economista". Entonces entendían que era seminarista o comunista, lo cual era igualmente un desastre para estos trabajadores, clase obrera realmente militante. Para ellos ser seminarista también era un desastre. Mientras que a mí me entendían porque hablaba todavía porteño, en aquella época. Y claro, cuando descubrían que era alemana, me preguntaban si no tenía un empleo en Alemania para ellos. Fue la época de la gran emigración: tres millones de españoles que se fueron a Europa. Es algo que hay que recordar a esta altura de los acontecimientos con respecto a la migración. Así que [la estancia en la campiña cordobesa] fue una entrada muy interesante a este país.

\section{R: Nosotras pensábamos que quizás habías estado trabajando en un archivo, como lo estuviste más tarde en Cuba...}

VS: ¡No, no! Realmente pasábamos mucho tiempo, días, en el campo: en plantaciones de garbanzos, en los olivos, durante las cosechas... Y hablábamos con la gente, entrevistándolos. Juan ya había hablado con los terratenientes absentistas, que apenas aparecían en las propiedades. Los capataces, los administradores, eran los que estaban allí. Pero las cuadrillas de trabajadores y trabajadoras llegaban por semanas, venían de la sierra, y hablábamos con ellos sobre sus ideas políticas, precisamente sobre la estabilidad del latifundio. Yo hablaba con las mujeres y él hablaba más con los hombres. Fue mi experiencia preantropológica de etnografía.

\section{R: ¿Y habías leído ya a Pitt-Rivers?}

VS: Nada. Esto fue antes de hacer antropología. No había tenido ningún contacto previo. [El trabajo de campo en Andalucía] fue una experiencia debida a mi matrimonio. Supongo que siempre he sido muy curiosa, me relaciono bien con las personas y entonces me fascinaba todo esto. 


\section{perifèria}

Número 9, diciembre 2008

www. periferia. name

\section{R: Además de en Andalucía, también has estado en Oxford, Cuba y Brasil. Nos preguntábamos, ¿cómo terminaste dando clases de antropología en la UAB? ¿Qué relación tenías con Barcelona?}

VS: Ninguna. Vine con mis hijas en el año 75, en el último barco que entró en el puerto de Barcelona antes del cierre del puerto por los sindicatos como protesta por el asesinato de los últimos cinco ejecutados por Franco; entre ellos el "Txiqui", que está enterrado aquí, en el cementerio de Cerdanyola. $Y$ vine aquí porque Franco prometía morirse y Juan decidió volver. Antes pasó un año en París, colaborando con Ruedo Ibérico, "la editorial" española en el exilio. Juan volvió y entonces se planteó la pregunta de qué íbamos a hacer yo y las niñas. Entonces otra vez me lo pensé -soy un poco lenta en mis decisiones-, me lo pensé durante un tiempo y decidí que sí. Empaqueté mis libros, empaqueté a mis hijas y nos embarcamos porque con los libros ir en avión era imposible- en un Trasatlántico en Santos, que es la parte baja de São Paulo. Después de dos semanas en barco, vía Lisboa, llegamos a Barcelona. Y así llegué justo antes de la muerte de Franco. Me acuerdo muy bien. Fuimos al Palacio de Deportes a aquel acto extraordinario de Lluís Llach, cuando todavía estaba unificada I'Asamblea de Catalunya, antes de la fractura en partidos múltiples anterior a las elecciones. Estaba todo el mundo con velas y Lluís Llach cantando... ¡Fue una cosa tan impresionante! Fue un momento muy bonito. El dictador estaba ahí en la cama enchufado, con el manto de la Pilarica en algún sitio de su cuerpo y a punto de fenecer. ¡Pero lo gestionaron tan extraordinariamente, de manera tan políticamente eficaz! Porque claro, como tardó tanto en morirse, el cava en las neveras se estaba congelando. ¡La gente nos cansamos tanto de todos estos documentales de animales y caballos en la televisión...! Fue una cosa muy stage managed, es decir, preparado con mucha astucia para evitar una ruptura política repentina. Si no hubiera sido así, la gente hubiera salido a la calle. 


\section{perifèria}

Número 9, diciembre 2008

www. periferia.name

\section{R: Y más concretamente, ¿qué te encontraste en lo que era entonces el "Departament d'Història de les societats precapitalistes i Antropologia Social" en la Universitat Autònoma de Barcelona?}

VS: ¡No, no, si todavía no existía! Yo llegué en el 75 y me pasé tres años más, hasta el 79, haciendo medio año aquí y medio año en la universidad de Campinas, porque aquí no tenía trabajo. Me presenté, junto con Ignasi Terrades a una plaza en la UB, creo que en el 76 o en el 77, y contrataron a Ignasi (también era comprensible). Yo iba y venía. Entonces estaba escribiendo un libro sobre la historia del café en São Paulo. ${ }^{8} \mathrm{Y}$, jera tan solitario estar en casa... escribiendo y escribiendo! Conocí a muy poca gente. Lo que sí que había era un grupo de mujeres en Cerdanyola. Constituimos muy rápidamente el Grup de dones feministes de Cerdanyola, y creamos "El safareig". Esto era para mí una salida. Y una comunicación con personas.

\section{R: ¿El safareig fue incluso antes que la universidad?}

VS: Sí. Y después un día fui a visitar a Ramón Valdés a Sant Cugat y me invitaron a dar unos seminarios en la Universidad. Me acuerdo de un seminario sobre Meillasoux en el que estaba Àngels Pasqual y cierto público. Después, en el 79 creo que fue, se convocó una plaza, una placita de aquellas y me presenté. Y tardó, fue un poco complicado. Así, empecé a dar clases aquí, pero como pinche. Éramos - y esto es interesante -, éramos exactamente Ramón Valdés, Aurora González, Joan Frigolé y yo. Después de mí vino muy rápidamente Teresa San Román. Éramos cuatro y después cinco durante bastante tiempo. Es decir, éramos una sección de historia.

\footnotetext{
${ }^{8}$ Stolcke, V., Cafeicultura: homens, mulheres e capital, 1850-1980, São Paulo: Editorial Brasiliense, 1986 (edición en inglés de 1988)
} 


\section{perifèria}

Número 9, diciembre 2008

www. periferia. name

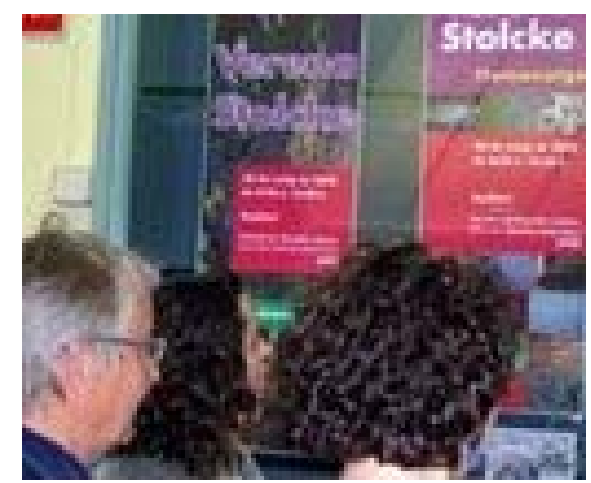

Verena Stolcke, con las entrevistadoras, delante del expositor de la Hemeroteca de la Facultad de Filosofía y Letras de la UAB, dedicado a su obra en el marco de los actos de celebración de su jubilación.

Fotografía: Montserrat Clua

\section{R: ¿Y qué líneas de investigación había entonces? ¿Cuál fue tu aportación?}

VS: Aurora González hacía teoría del parentesco, más teoría del parentesco que epistemología. Ramón Valdés, historia de las religiones comparadas. Ramón tiene una formación filosófica alemana muy interesante. Yo estaba todavía acabando mi libro sobre el café en São Paulo y hacía estos cursos tan divertidos. El sistema era anual y las asignaturas duraban nueve o diez meses. Yo hacía las introducciones. Y claro, las introducciones eran muy agitadas y críticas: de Engels y "la familia", y Leach y la "ignorantia paternitatis"...Y antropología política. Aprendí mucho. Eran esas introducciones muy generales pero con mucho trabajo. Muy animado sin duda. Yo siempre pensé con respecto a la docencia, tanto en la docencia a nivel de licenciatura como a nivel del tercer ciclo, que no estoy de acuerdo con la especialización extrema, que las personas tienen un tema y enseñan exclusivamente sobre ese tema exclusivamente. Entonces, yo organizaba unas introducciones muy amplias y variopintas. También en tercer ciclo. ¿Te acuerdas Montse? [Se dirige a Montserrat Clua] Estoy pensando en recuperarlo. Dos o tres 


\section{perifèria}

Número 9, diciembre 2008

www. periferia. name

veces di un curso sobre "El estado de las utopías", que era una maravilla realmente. ¡Lo pasamos muy bien! Después otro sobre cazadores y recolectoras. Son ocasiones para aprender. Yo no estoy de acuerdo con que la gente se especialice de esta manera, tan pronto, en la enseñanza.

\section{R: Bueno, ya hemos hablado antes de que gracias a la red de intercambios Erasmus el departamento se ha dado a conocer internacionalmente.}

VS: Sí, sin duda alguna. Al principio, cuando se diseñó desde la Comisión Europea el programa Erasmus de intercambios europeos, el rumor que corría era que en un país del sur de Europa lo que la gente hacía era ir a la playa, que esto era poco serio. Entonces claro, los que llegaron aquí descubrieron que sí que hacíamos, que hacemos antropología. Antropología con una tradición más bien anglosajona, más que francesa, - aunque Aurora está muy al tanto sobre la antropología francesa -. ¡Y descubrieron que se trabajaba! Esto realmente fue divulgando el que, por una parte, Barcelona es una ciudad muy bonita, es interesante y que, además, se puede hacer antropología también de manera interesante desde la periferia. Porque eso de estar en los márgenes en este país es una cosa... Yo siempre he pensado que es una cosa bastante interesante, porque te permite mirar todo el panorama del centro teórico y conceptual; es decir de Estado Unidos, Inglaterra, Francia... Que además no se comunican entre ellos, es una cosa bastante sorprendente.

\section{R: Son diferentes países que tienen diferentes idiomas...}

VS: Y las tradiciones coloniales son muy potentes, ¿no? Es decir, ¡que una Marilyn Strathern, "la antropóloga" inglesa que ahora se está jubilando, profesora de Cambridge, no lea a Françoise Héritier, "la especialista" francesa sobre parentesco...! Las dos trabajan sobre esto y no se leen recíprocamente. A mí me parece absolutamente sorprendente. $\mathrm{Y}$ además, muy sintomático de la falta de comunicación que hay entre los grandes ámbitos institucionales en las ciencias 


\section{perifèria}

Número 9, diciembre 2008

www. periferia.name

sociales, no sólo en la antropología.

R: ¿Crees que son importantes entonces las redes personales, para estos intercambios?

VS: También. Sí, sí, son importantes. En este departamento, supongo que soy... el recurso..., "la viajante" de la antropología. A lo largo de las décadas he conocido a mucha gente, muchos colegas, y esto tiene muchas ventajas. Era obvio que el tema Erasmus lo iba a gestionar yo, precisamente por estas vinculaciones. Y creando nuevos lazos. De ahí viene también el Master Oficial Europeo que tenemos. ${ }^{9}$ Es muy divertido. Es un master periférico, un convenio entre la UAB, Estocolmo, Ljubljana en Eslovenia, Viena en Austria, Lyón y Maynooth en Irlanda. Es decir, que es la periferia otra vez, y por eso yo creo que funciona y nos entendemos bien.

Montserrat Clua: En cierta medida, esto está relacionado con lo que estabas explicando antes de que Marilyn Strathern y Françoise Héritier no se leen entre ellas. Para nosotras estar en la periferia es una ventaja, porqué las leemos a las dos. Quizás el problema es nuestra visibilización hacia fuera: nosotras podemos leerlas, pero como disciplina, darnos a conocer a fuera nos cuesta mucho más. Quizás esto nos hace aún más periféricos...

VS: A ver, por una parte está esta gran ventaja. Y, por otra parte, en los últimos años, a ver... ¿cuándo se crea la licenciatura? En el 92, ¿no?

\section{M: Es que es muy reciente...}

VS: Es muy reciente. Y nunca hay que olvidar los cuarenta años de dictadura durante los cuales no había ciencias sociales, había individuos (que no individuas, además). Esto es todo muy reciente. Pero, por otra parte, yo creo que es muy

\footnotetext{
${ }^{9}$ Se refiere al Máster Oficial Europeo que se imparte en la UAB denominado CREOLE.
} 


\section{perifèria}

Número 9, diciembre 2008

www.periferia. name

interesante lo que decías en segundo lugar, lo de que "sí, nosotros miramos al mundo pero el mundo no nos mira a nosotros". Esto ha cambiado hasta cierto punto. Porque España y Portugal eran, especialmente España, hasta los años 70 (e incluso entrando en los 80), un lugar considerado exótico por los centros del saber antropológico, terreno para hacer etnografía. Tienes toda una escuela de antropólogos europeanistas en Estados Unidos; es decir, antropólogos que estudian en Europa (en Italia o en España). Y eso ha cambiado. Hoy creo que llegan muchos menos doctorandos con proyectos muy ingenuos en parte, pretendiendo que aquí van a encontrar las pequeñas comunidades claramente circunscritas donde puedan hacer investigación. Hubo una época, más recientemente, en que venían para estudiar la "cuestión catalana". No sabían nada de nada. Y sobretodo no sabían nada sobre la cuestión nacional, porque en Estados Unidos no tienen ni idea. Esto yo creo que ha ido cambiando y España ha dejado de ser objeto de estudio etnográfico. Por otro lado, la mayor parte de la investigación desde el gremio antropológico en el estado español se ha realizado en el país mismo. Es relativamente reciente ir a lugares más o menos distantes: ir a Indonesia, como Hugo Valenzuela, o a Australia como Anna Piella. Pero es como en América Latina: los grandes centros son México y Brasil, y Perú hasta cierto punto. Y la gente investiga en el propio país. Esta tradición un tanto colonial de ir al "quinto pino" a buscarte los "autóctonos puros", como hizo Lévi-Strauss en el interior de São Paulo... Esto nunca se ha llevado en la periferia, porque yo creo que la antropología era mucho más politizada. Por estar más próxima, justamente, a los acontecimientos y la coyuntura, y a las características y las cuestiones fundamentales del propio país.

Laura Tamarit: Cambiando de tema, siempre nos has enseñado que "En toda teoría, hay algo de biografía" y creemos, que esto se aplica muy bien en tu caso... 


\section{perifèria}

Número 9, diciembre 2008

www.periferia. name

VS: Sí, sin duda alguna. [Ríe]

\section{L: ¿Cómo una joven alemana emigrada en Argentina termina estudiando antropología social en Oxford?}

VS: Eso es una historia un tanto peculiar. Por una parte, hay una cuestión general que es muy interesante. Si miramos la profesión en Inglaterra (sobretodo en los grandes centros que son Londres, la London School of Economics, Oxford y Cambridge, o Manchester incluso), nos encontramos con un montón de lo que en Inglaterra llaman expatriates; es decir, antropólogos que en realidad vienen de Australia, de Sudáfrica, como Kuper, etc., que tampoco son de ahí. Y yo creo que esas trayectorias móviles algo tienen que ver, te condicionan hasta cierto punto para una mirada antropológica.

En el fondo fue pura casualidad que hiciera antropología en Oxford, por una razón burocrática muy importante. Como os explicaba, claro, yo no tenía formación universitaria. Fui secretaria en Alemania. $Y$ después asistente de investigación en Stanford, porque me quería ir de la familia y encontré este anuncio de un empleo en Stanford con un equipo de investigación, y me lo dieron. Fue una cosa inusitada. ¡En Munich estaba todavía! En Stanford hacía dos cursos nocturnos. Uno de antropología, porque me pareció interesante; y otro de apreciación musical, música clásica, pues me gusta mucho la música. Y conocí al padre de mis hijas y así llegue a Oxford. $Y$ en Oxford se puede todavía, sin una licenciatura, sin un grado, ser admitido en la universidad, hacer un master, que era el diploma. Debido a esta historia tan movida (Argentina, después había estado en Colombia con este equipo, en Estados Unidos, etc.), pues me aceptaron. Me presenté en el Instituto de Antropología Social en Oxford con mis antecedentes [ríe], y efectivamente ¡me aceptaron! Y así fue como empecé a estudiar antropología. Y también tenía algo que ver qué otras posibilidades había, que otros campos de estudio había. Yo había hecho este cursillo de antropología en Estados Unidos, que era una introducción. Y 


\section{perifèria}

Número 9, diciembre 2008

www.periferia. name

otras posibilidades eran hacer un PPE, es decir un diploma en Filosofía, Ciencias Políticas y Economía (Philosophy, Political Science and Economy). Y no me iba, eso no me interesaba, pues me interesé especialmente por la antropología. Yo había viajado y fue así como empecé.

El otro día fue tan bonito porque con relación al homenaje, mi hija menor se puso en contacto con mi tutor en Oxford, Peter Rivière (que las conoce de así de chiquitas, ¿no?), y él comentaba que se acordaba muy bien de cuando yo llegué y le fui asignada a él como estudiante. Él hacia dos meses que había acabado el doctorado y había sido contratado por el instituto al nivel mas bajo, como lector, y se acordaba muy bien de que yo no tenía ¡ni noción! de que era esto de la antropología. Pero bueno, después trabajé mucho. Fue un año extremamente trabajoso.

\section{L: ¿Y cómo crees que te ha influido el haber estudiado en Oxford?}

VS: Bueno, a ver... [ríe]. Estaba estudiando, estaba teniendo hijas, y por eso, no tenía tiempo para participar de la vida normal, habitual, de los estudiantes, de mis colegas. Tenía compañeros muy variopintos, en edad y procedencia. Éramos un grupo de treinta y tantos muy interesante. Pero había un grupo de la edad en que se estudia que iban al bar, al pub, con los profesores el viernes después del seminario y estas cosas. Yo todo esto no lo pude hacer. Era lo que se llamaba en aquella época, y todavía existe, una madure student, una estudiante madura en términos de edad. Tenía 26 o 27 años.

¿Como me influyó Oxford? En adquirir una cosa que ya venía de Estados Unidos y que me movía y me preocupaba enormemente... Dos temas en realidad que me preocupaban. $Y$ era el hecho que yo nací en el 38 y en la semana de la invasión de Austria por los nazis. Y lo típico, como ha pasado aquí: hubo un silencio total después de la guerra, en las familias nadie hablaba. Nadie hablaba del horror de la II Guerra Mundial ni del exterminio de los judíos. Y eso me tenía absolutamente 


\section{perifèria}

Número 9, diciembre 2008

www. periferia. name

atravesada. La pregunta fue: ¿cómo fue posible? Sabía poco, pero algo sabía. Me preguntaba cómo fue posible, qué es lo que pasó y qué es esto del racismo. Por otra parte éramos muy lanzados en los años 60. Esto ya fue en el 65-66. Y recuerdo muy bien el 68, el mayo en Francia. Éramos muy radicales, contra la familia burguesa y todas estas cosas. Entonces vivíamos de acuerdo a estas ideas radicales, que también tenían que ver con la antropología que yo estaba haciendo. Porque claro, desde la antropología aprendí bastante rápidamente que la familia no es una, que esto no es un fenómeno universal, sino que son muy diversas. Y por lo tanto me parecía que tenía argumentos para discutir con mi madre sobre si había que casarse, sobre si había que bautizar las hijas, etcétera. Sabía que en otros pueblos, en otras sociedades, esto no se hacía. Y no quería que me viniera con estas ideas normativas tan exclusivas. Era vivir realmente, aprender muchísimo, y trabajar y estudiar muchísimo, pero muy relacionado con las interrogantes y las dudas que tenía. Y la otra era la sexualidad. La virginidad. Yo me crié en Argentina, que era bastante parecido a aquí en aquella época, ¿no? Una chica tiene que llegar virgen a... bueno, tiene que llegar virgen a donde sea [ríe], y si se casa, idebe llegar virgen al matrimonio! Es deseable que contraiga matrimonio, ¿no?

Yo en Oxford hice indiología con David Pocock, que era una persona encantadora y además un especialista en la India. En aquella época ya leí a Louis Dumont, Homo Hierarchicus, a Kathleen Gough, sobre los Nayar. Entonces todas estas etnografías y estos análisis eran fantásticos para pensar: sobre cuerpo y alma, sobre la pureza..., y ¡muchos más! Eran fantásticos para poner en cuestión toda esta moral, en el fondo de la clase media, vigente entre las familias de donde veníamos. Así que fue un aprendizaje que tenia mucho que ver con la vida misma. Después, claro, a continuación fuimos a Cuba, y como no podía hacer mucho trabajo de campo, acabé en el archivo. $Y$ con estos fantásticos documentos que me permitieron estudiar de una manera absolutamente sistemática una sociedad esclavista con una legitimación racial explícita, absolutamente explícita. Y una reglamentación de los 


\section{perifèria}

Número 9, diciembre 2008

www.periferia.name

matrimonios según "razas" también absolutamente explícita. ${ }^{10} \mathrm{Y}$ ahí sí que fue un descubrimiento para mi ifantástico! Después de esto ya nadie me podía contar nada sobre el matrimonio como camino recto hacia la salvación de las almas, etcétera...

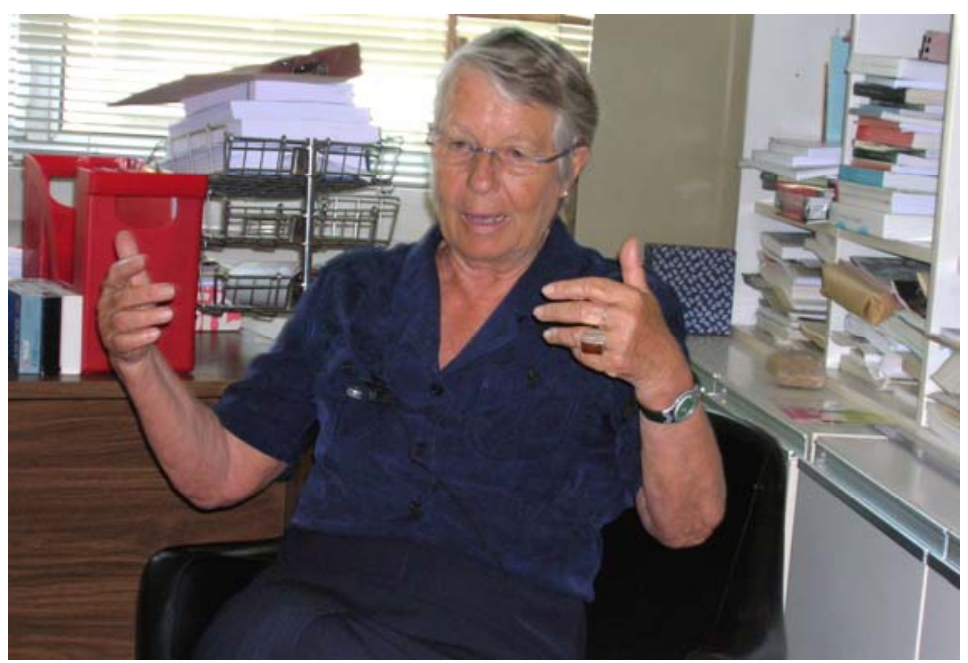

Fotografía: Montserrat Clua

L: ¿Y más específicamente, destacarías alguna persona o personas que consideres que te marcaron en tus inicios o que hayan sido muy influyentes a lo largo de tu trabajo académico?

VS: Sí. Bueno, Martínez Alier, sin duda alguna, que ya estaba mucho más avanzado en su formación, y la estancia y la experiencia en la campiña de Córdoba fue muy impactante. Yo venía ya de Estados Unidos de una militancia, del movimiento

\footnotetext{
${ }^{10}$ Stolcke, V., Racismo y sexualidad en la Cuba colonial, Madrid: Alianza, 1992.
} 


\section{perifèria}

Número 9, diciembre 2008

www. periferia. name

estudiantil y del movimiento por los derechos civiles de la población negra, que tenia todo que ver con mis antecedentes. Me apunté justamente porque tenía este pasado, es decir, ser alemana. Pero me influyó sin duda alguna mi tutor, que fue extraordinario, Peter Rivière. Porque fue siempre respetuoso, siempre me animaba, era constructivo, etc. Porque esos trabajos semanales a veces debían ser un desastre total ¿no? Pero él me animaba, me hacia críticas y me inspiraba. Y después me orientó también en la tesis de doctorado. Él no tenía ni idea ni sobre el Caribe, menos todavía sobre Cuba y menos todavía sobre la Revolución cubana del 59. Y su doctoranda se va a Cuba, y iencima! por razones prácticas se pone a hacer una tesis en lo que ahora llamamos antropología histórica. En aquella época, en Oxford, el modelo era el modelo funcionalista ahistórico sincrónico. Y Peter lo leyó todo, lo revisó y me animó. Fue fantástico.

Otro que me influyó mucho (pero esto ya fue fuera de la antropología, que es uno de estos autores, de estos pensadores, que lo conocí muy bien), fue Eric J. Hobsbawm. Él fue la primera persona en donde vi un planteamiento que mostraba la contradicción de la modernidad. Es decir, no en estos términos pero sí una tesis que permitía empezar a pensar: "¿Por qué el racismo?" como ideología legitimadora de la desigualdad en una sociedad que, por otra parte y como os cuento siempre, exalta la autonomía, la libertad y la igualdad de los sujetos modernos. A Hobsbawm lo llegué a conocer cuando publiqué un primer artículo en una revista de historia en Inglaterra, que es muy conocida, Past \& Present. Y fue él una de las personas que lo leyó, se discutió y lo publicaron. Ciertamente, fue muy importante.

Después el grupo History Workshop, que empezaba entonces. Era un grupo de historiadores sociales marxistas, más o menos heterodoxos, muy jóvenes en aquella época, que empezaron a organizar primero unos seminarios, ahora tienen una revista... Estuve en contacto con ellos porque empezaron en Oxford y me invitaron a hacer un seminario sobre lo que estaba haciendo sobre Cuba. Porque 


\section{perifèria}

Número 9, diciembre 2008

www. periferia. name

claro entonces Cuba (ipara mi fue una suerte!), estaba de moda por la revolución del 59. Cuando me puse en contacto con ellos era el 68-69; es decir, apenas 10 años más tarde. Todavía no había tenido lugar el descrédito - con razón -, de la revolución autoritaria de Fidel. Y entonces ahí también aprendí mucho, y esto me reforzó también la perspectiva histórica.

\section{L: A lo largo de tu trayectoria intelectual has mantenido un interés constante por las cuestiones relacionadas con la intersección entre raza, género y clase. ¿Cómo has vivido los cambios o la evolución del estudio de estos temas y cómo crees que se encuentra el estado de la cuestión en la actualidad?}

VS: Es una buena pregunta porque lo estaba pensando el otro día. Y vamos a ver como continuamos investigando ahora con el AHCISP. Porque estaba pensando que hay una especie de movimiento pendular, ¿no?, desde el artículo de Talking Culture, ${ }^{11}$ entre este culturalismo nacionalista férreo en Europa y después el movimiento de reacción, que son todas estas identidades ambivalentes. Estoy viendo artículos por todos sitios sobre mestizaje, hibridez,... etc. Mi opinión es que ahora, - como decimos con toda razón y como estamos haciendo con el grupo de investigación AHCISP-, lo que hemos de hacer es estudiar los sistemas de clasificación social. Es decir, si quieres una terminología menos pedante, lo que siempre me ha interesado son las formas de estructurar y explicar, justificar, sistemas sociales de desigualdad. Que siempre tiene un componente de género, sin duda alguna. Pero en este campo, es muy curioso que en los últimos treinta años haya habido un movimiento pendular. Desde Francia, sobretodo en los años 80 , de un nacionalismo asimilacionista férreo. $Y$ ahora en Estados Unidos, hay que mirar

\footnotetext{
${ }^{11}$ Stolcke, Verena: "Talking Culture: New Boundaries, New Rhetorics of Exclusion in Europe", Current Anthropology, Vol. 36, No. 1, Special Issue: Ethnographic Authority and Cultural Explanation (Feb., 1995), pp. 1-24.
} 


\section{perifèria}

Número 9, diciembre 2008

www.periferia.name

un poco la geopolítica de esto, o en Suecia, etc., esta manía, este énfasis en las mezclas, que, como estamos mostrando, en realidad refuerzan la idea de identidades puras.

Entonces, lo que yo me pregunto ahora es: ¿qué va a pasar con la actual crisis del petróleo y todas sus consecuencias (la creciente desigualdad Norte-Sur y los problemas en los países centrales)? ¿Qué va a pasar concretamente con la inmigración y con estos programas de deportación? Como bien dice Josep Ramoneda, ocho millones de personas deportadas de Europa... ies realmente espeluznante! Y ¿cómo se va a justificar? Es decir, ¿cómo va a cambiar otra vez la justificación ideológica, el discurso sobre los inmigrantes? Yo me temo que esto se va a notar bastante. Ya se oye otra vez este tipo de argumentos: "Que si les dan más becas para el comedor a los niños inmigrantes...". Incluso con gente que debería saberlo mejor, que han hecho antropología, te dicen: "sí, este argumento se explica porque ahora hay muchos más inmigrantes y hay una proporción más alta de niños de familias inmigrantes en proporción con los de aquí, en las escuelas". Es decir, que son críticos al rechazo de los inmigrantes pero incorporan parte del argumento. En vez de decir: "Y, ¿que diferencia hay, que los padres o las madres sean inmigrantes, para que les den una beca? Si la necesitan, la necesitan. Los de aquí como los que vienen de fuera." No, pienso que se avecinan unos tiempos un poco preocupantes...

Y lo que se plantea siempre de nuevo es esto: cómo se legitiman las crecientes desigualdades que están emergiendo y las expulsiones de gente de afuera. $Y$ en este sentido, ya no creo que sea en términos racistas, porque el racismo es un discurso demasiado desacreditado en esta vieja Europa. Pero hay muchos discursos posibles, relacionados con las fronteras, los muros,... 


\section{perifèria}

Número 9, diciembre 2008

www.periferia. name

\section{L: ¿O sea, que crees que realmente no se ha avanzado mucho hacia una sociedad más igualitaria más allá de las teorías feministas o antirracistas, no?}

VS: No, definitivamente no. Yo creo que no son movimientos lineales, sino que son movimientos coyunturales dependientes del contexto. Ayer o antes de ayer, estaba terminando una clase en los postgrados y lo vi muy claro: en 1973, con la primera crisis del petróleo que concluye los veinte años de crecimiento económico sostenido después de la II Guerra Mundial, enseguida cambió la forma de percibir a los inmigrantes. Que eran los tres millones españoles, que en parte vuelven, en parte se quedan. Y que eran muy bienvenidos porque hacía falta mano de obra y eren gente muy bien formada. De pronto, pero, los discursos cambian, y los inmigrantes se convierten en extranjeros indeseables. Ahora estamos en 2008 y con otra crisis del petróleo bastante más grave, creo yo. Y esto se notará otra vez. Son movimientos, pero entremedio también tiene que ver con quién gobierna, qué gobierno está en el poder. El PP fue terriblemente violento con respecto a la cuestión de la inmigración. En cambio, con el primer gobierno de Zapatero vivimos unos cuatro años de una tranquilidad notable, ¿no? Es decir, no sólo con el programa de regulación importante, sino en general el clima había cambiado... Ahora se nota que está cambiando otra vez.

\section{L: Precisamente, en los últimos tiempos, te has dedicado a estudiar el tema de la construcción de la categoría colonial del mestiz@...}

VS: Sí, este tema lo trabajamos con el $\underline{\mathrm{AHClSP}}$, nuestro grupo de investigación formado por Josep Lluís Mateo, Montserrat Ventura, Montserrat Clua, Alex Coello, Mónica Martínez, Maite Ojeda, J oan Muela, Alexandre Surrallés y Salvador Queralt. Lo que nos interesó desde el principio fueron todas aquellas situaciones en donde esas ideas de fronteras claras - es decir, la idea de la cultura como una especie de caja cerrada internamente homogénea -, no se sostenían. Fue de ahí, de esa idea, 


\section{perifèria}

Número 9, diciembre 2008

www. periferia. name

cuando empezamos a buscar cuales son las situaciones que eran como de puente, de puente entre identidades concebidas como colectivas, como cerradas. Ahí nos encontramos con el pluralismo médico en Tanzania de Joan Muela, la cuestión nacional que estudia Montse Clua y que no permite la mezcla,... Y yo, como he trabajado sobre la historia colonial de Hispanoamérica, entonces un día me pregunté: ¿y los "mestizos", de donde salieron? Entonces tuve una conversación con Josep Lluís Mateo y comentamos qué pasa en el mundo árabe musulmán: ¿existen mestizos? Pero el momento clave de mi interés fue durante la invasión de Irak, una situación que me llevó a hacer clase delante del edificio del Gobierno Civil, en la calle, en las llamadas classes al carrer ${ }^{12}$. $Y$ entonces estuve mirando la historia del Imperio Otomano, es decir, los antecedentes del reparto colonial del Oriente Próximo. En esto me encontré con otro gran imperio donde hubieron mezclas y me pregunte qué categorías había allí. Luego hablando con Josep Lluís Mateo, estuvimos comparando y pensando a ver qué pasaba allí, cómo categorías análogas a los mestizos en América Latina. $Y$ descubrimos que no hay. Fue entonces cuando decidí escribir a unas historiadoras en Estados Unidos, a través de otra colega que trabaja en Oriente Próximo, y les pregunte qué categorías había. En Estados Unidos se conoce bastante bien la historia de América Central y América del Sur, por lo que no les era desconocida la categoría de mestizos. Una me escribió que no, que no había categoría parecida en el mundo árabe porque no debían haber diferencias de raza. La otra me escribió también que no, que no había categoría porque no debían haberse mezclado... Entonces, claro, las dos respuestas confirmaban precisamente el interrogante; es decir, que se trata de construcciones históricas. Las diferencias no son diferencias, lo que es relevante en lo que se refiere a las diferencias no son los hechos diferenciales, sino el contexto político e histórico.

\footnotetext{
${ }^{12}$ Expresión en catalán de "clases en la calle".
} 


\section{perifèria}

Número 9, diciembre 2008

www.periferia.name

\section{L: Entonces, ¿se podría decir que el mestizaje es una ideología que esconde una nueva forma de colonialismo?}

VS: Sí, pero no tanto colonialismo, sino una amnesia total con respecto a sus orígenes, los orígenes del concepto. Lo que sí que esconde es el hecho de que, para que tengas una mezcla, tienes que construir primero una separación. Entonces, cuando hablamos de mestizaje cultural, lo que estamos confirmando es que, los marroquíes y los catalanes por ejemplo, son distintos culturalmente... Culturalmente casi esencialmente, ¿no? Ahí llegamos a hacer el libro, “Identidades ambivalentes". ${ }^{13} \mathrm{Y}$ por ahí vamos. $\mathrm{Y}$ ahora vamos a ver como continuamos con esta cuestión.

L: Pasando de la teoría a la práctica, ¿Cuál es el papel que crees que puede o debe tener la disciplina para ir más allá de la construcción teórica y ser motor de una acción transformadora del cambio social?

VS: En primer lugar pienso que cada cual tiene el derecho, o debería tener el derecho y también la posibilidad, de desarrollar su investigación y su docencia según sus curiosidades y sus inquietudes. Es decir, quienes me dan pena son los que no tienen inquietudes, que también hay. $Y$ en el ámbito académico universitario, esto debe ser muy aburrido, ¿no? Pero, claro, yo siempre he vinculado - pero no conscientemente, sino simplemente porque así fue como crecí , lo que estudio y las preguntas que me planteo, las curiosidades que tengo, también con trabajo práctico. Porque yo creo que una cuestión fundamental es la docencia; o mejor dicho, la pedagogía sociopolítica que podemos hacer.

${ }^{13}$ Verena Stolcke y Alexandre Coello (eds.), Identidades ambivalentes en America Latina (siglos XVIXXI), Barcelona: Edicions Bellaterra, 2008. 


\section{perifèria}

Número 9, diciembre 2008

www.periferia.name

Cada tanto nos llegan (bueno, cada vez más), demandas de la televisión o de la radio, si tenemos a alguien para hablar sobre temas relevantes. El otro día, hace una semana o diez días, fui a "Hora 25", un programa de Àngels Barceló. Y fue justo después de los problemas en África del sur. Es decir, de los enfrenamientos entre pobres: pobres sudafricanos contra inmigrantes mozambiqueños y de Zimbabwe. Entonces la cuestión que estaban planteando era si esto era racismo. Fui y hablamos media hora, o un poco más. Y ahí puedes explicar muchas cosas y lo oye mucha gente. Yo creo que esto es un tipo de actuación. Yo soy también del movimiento feminista, y por ahí también podemos hacer muchísimo, contribuir a plantear preguntas y a hacer pensar a la gente desde una perspectiva crítica.

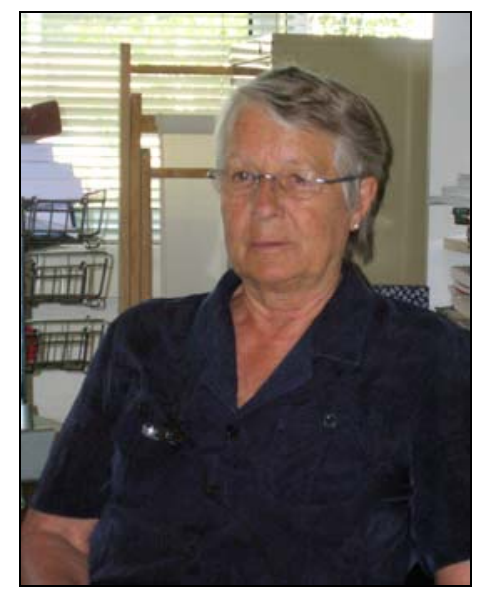

Fotografía: Montserrat Clua

L: Ya para ir terminando, sabemos de tu especial olfato para prever cuales van a ser los temas o cuestiones más importantes, tanto a nivel teórico como político, en el futuro. ¿Cuáles van a ser los temas y aproximaciones teóricas que se van a trabajar en las ciencias sociales en los próximos años?

VS: Eso sí que es difícil decirlo...Yo pienso más bien que hay un proceso un poco 


\section{perifèria}

Número 9, diciembre 2008

www. periferia. name

contradictorio en como se diseñan o en como se desarrollan los temas de investigación en las ciencias sociales, que es bastante distinto de las ciencias exactas. Por una parte, no hay ninguna duda de que las modas son las modas. Y solo hay que ver los temas de doctorandos y doctorandas, ¿no? Por ejemplo, hubo años en los que sólo se trabajaba el tema de la inmigración... Yo ya decía ¡prohibido! O paguen una tasa o comisión a un colectivo de inmigrantes, porque realmente... iqué falta de imaginación! Entonces las modas van juntas con un poco de dinero, que también atrae investigación. Pero por otra parte también hay quienes, con bastante atención, se plantan críticamente ir contra estas corrientes y lenguajes tan módicos. Yo recomiendo realmente ser, tratar de no subirse a un caballo de estos entrenados para ir por el recto camino de la moda. Si hechas un vistazo en las revistas internacionales, es tremendo. Puedes hacer compartimentos cronológicos de los temas que están de moda en cada momento.

\section{L: Finalmente, ¿nos podrías hacer un pronóstico sobre el futuro de la antropología, como ciencia y como profesión?}

VS: Vaya, es difícil... Bueno, también depende de los recursos que haya, ¿no? Pero a ver, en este país, y teniendo muy en cuenta el papel absolutamente importante que está jugando este departamento en el diseño del grado - es decir, en un grado de cuatro años, etcétera -, yo soy optimista. Creo que realmente se ha hecho un proceso importantísimo y muy bien llevado, con un programa nuevo que creo que también es muy interesante. Estamos, por cierto, volviendo a incorporar la antropología biológica, y ya era hora. $\mathrm{Y}$ esto fue un descubrimiento de hace poco, dos o tres años. Entonces, en este sentido soy optimista.

Mmm..., en general, yo creo que nos tendríamos que vender un poco mejor. Porque desde la antropología podemos hacer contribuciones en campos distintos y actuales, como la informática, etc. Podemos hacer contribuciones muy importantes y muy valiosas. Justamente por el método comparativo y por la etnografía y el 


\section{perifèria}

Número 9, diciembre 2008

www. periferia. name

trabajo etnográfico de verdad (no esto de las entrevistas y las historias de vida, que son un procedimiento muy limitado en términos de información). Pero tenemos que vendernos más. Ahí está el ICA y estamos intentando avanzar en este sentido.

\section{L: ¿Y consideras que el futuro de la antropología pasa por un cambio en el objeto de estudio? Yo pienso quizás hay que vender otra imagen de la antropología o cambiar el objeto de estudio...}

VS: Menos exótica, ¿no? Yo lo que no creo que sería adecuado es esta imagen del antropólogo tipo Indiana Jones, este tipo de imagen de quiénes estudian lo exótico en el quinto pino... Pero no es una cuestión de sustitución, sino de explicar claramente cual es realmente el objetivo y cuales son las posibilidades de la antropología: estudiar la experiencia humana en su diversidad en el espacio y en el tiempo. Mira, ique buena definición! Yo creo que esto capta el objetivo, acompañado de una metodología comparativa y etnográfica. Entonces esto es lo que tenemos que vender para salir de este rincón de lo exótico. Bueno, también tendríais que preguntaros a vosotras mismas porque estáis haciendo antropología, ¿no? ¿Qué es lo que explica vuestra opción por hacer la licenciatura? ¿Qué es lo que os atrae?

Difundir esta imagen de la antropología es importante. Que no es la única disciplina posible, porque esta fractura de las disciplinas también es problemática, ¿verdad? Pero desde la antropología realmente puedes ampliar tu horizonte, pensar de manera más relevante, más crítica, el mundo en que vivimos. Esto es importantísimo. Y se me ocurre que habría que organizar una mesa redonda con vosotras, des del ICA, justamente con esta pregunta. Es decir, cómo divulgar la antropología, hacerla atractiva, a partir de experiencias y opciones personales. Una serie de cuatro, cinco o seis personas, creo que estaría muy bien.

A nivel profesional también tendría que mejorar. Actualmente es un desastre. En ello estamos, en el diseño del grado, hablando de competencias... Yo creo que, a 


\section{perifèria}

Número 9, diciembre 2008

www.periferia.name

esta altura, comparando antropología con sociología, la situación laboral no es mejor para los sociólogos, ¿eh? Es decir, el contexto es fatal. Esto es un problema.

\section{L: Pues creo que ya está... Muchas gracias por colaborar con nosotras}

VS: De nada, ha sido un placer.

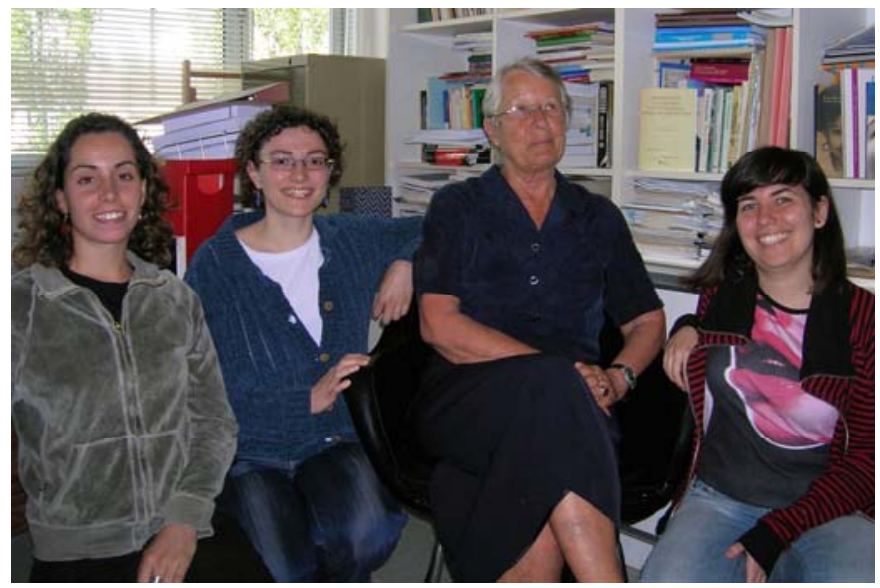

De derecha a izquierda, Laura Tamarit, Fina Ribas, Verena Stolcke i Roser Blasco Fotografía: Montserrat Clua 